\title{
Energy Efficient Driving Optimization of Electrical Vehicles Considering the Road Characteristics
}

\author{
Hasan Eroğlu and Yasin Oğuz
}

\begin{abstract}
Electric vehicles, which are an important part of sustainable energy technologies, occupy an important place in our daily life. More efficient use of electric vehicles will ensure more efficient use of sustainable energy sources. It is not possible for the human brain to determine the most efficient driving characteristics. In this study, energy efficient driving optimization of electric vehicles was realized. Along the route, optimum speeds were determined in terms of energy, by using the road and engine characteristics. Geographical information systems and genetic algorithm have been used effectively in the solution of the problem. The effectiveness of the proposed algorithm was revealed with many test studies. With this study, an algorithm that provides an energy-efficient driving for electrical vehicles was developed. The results will contribute to the development of electric vehicle technologies.
\end{abstract}

Index Terms - Electric Vehicles, Energy optimization Autonomous vehicle.

\section{INTRODUCTION}

$\mathrm{R}$ ANGE OF electric vehicles $(\mathrm{EV})$ is one of the most important parameters in the evaluation of EVs. Road condition, vehicle performance, driver profiles, traffic situation and similar factors are the main factors affecting the EVs range [1]. Increasing the efficiency of EVs can be achieved by developing battery, motor, communication, mechanical parts, shell, and similar technologies, as well as optimum vehicle driving according to the road conditions. The slope of the road and the number of bends in the road are the main road conditions that affect energy consumption.

HASAN EROĞLU, is with Department of Electrical and Electronics Engineering University of Recep Tayyip Erdogan, Rize, Turkey,(e-mail: hasan.eroglu@erdogan.edu.tr).

iD https://orcid.org/0000-0002-7233-5569

YASIN OĞUZ, is with Department of Electrical and Electronics Engineering University of Gumushane, Gumushane, Turkey, (e-mail: yasin.oguz@gumushane.edu.tr).

iD https://orcid.org/ 0000-0002-0324-0515

Manuscript received March 24, 2021; accepted April 19, 2021.

DOI: $10.17694 /$ bajece. 902485
Determining the ideal speed according to the slope and bend criterion of the road will reduce energy consumption considerably, allowing the EVs to travel over longer ranges. As known, it is very difficult for the driver to perform the most effective driving, considering the most efficient speed of the engine and the desired time to reach the destination depending on the slope and bend of the road. To this day, many studies have been conducted on the use of EVs more efficiently. Some of these studies have focused on identifying more economical road routes for electric vehicles. From these studies, a mathematical model was proposed [1] to find the fastest path for heavy vehicles by considering the slope of the road, radius of curves of the road, width, weight, carrying capacity and the sample application was carried out. The constrained shortest path (CSP) algorithm was developed, assuming the maximum and minimum battery capacity as the limit [2]. A new algorithm has been proposed [3] by considering the battery limit values and energy for determining an effective route. A new routefinding algorithm with data mining technique was introduced [4] by considering the speed characteristics of the driver from a data set. A dynamic route planning algorithm was developed [5] that calculates the energy consumption of the EVs in consideration of real-time traffic information. A multi-criteria route algorithm that provides time and energy optimization was proposed [6]. A study was conducted [7] using particle swarm optimization to find the least cost route between the two points. For this purpose, dynamic and static factors were considered. In this study, speed and road slope were accepted as constant.

A multi-purpose route optimization model based on model prediction control was created to determine the most appropriate way for drivers to manage wireless and plug-in charging states more effectively [8]. In all these studies, it was tried to determine a more efficient route.

On the other hand, some route independent studies were conducted to use EVs more efficiently. An optimization method was developed [9] by using indirect optimization method for serial hybrid EVs. In the developed method, the speed of the vehicle was regulated by considering the time, safety and comfort criteria and a reduction in energy consumption was recorded.

An Eco Adaptive Cruise Control System was developed [9] to increase the total energy costs and vehicle safety at the same time. The proposed controller captures the on-trip data to optimally adjust the speed of the EVs. The nonlinear model predictive control technique is used to adjust the vehicle speed. 
In another study, for EV drivers in the United States, optimization of the driving range was performed by [10], considering battery charge, electricity charge and other factors limiting the range. A concurrent optimization of the hybrid EVs was made using multi-purpose evolutionary optimization tools using powertrain and driving strategy variables [11]. In this study, it was emphasized the importance of choosing the right transmission range as well as the correct choice of power train as well as the correct choice of driving strategy to provide economical driving of Hybrid EVs. In another study [12], a speed optimization algorithm was proposed in the US to collect real driving data on a $4 \mathrm{~km}$ long motorway, allowing EVs to pass green traffic lights immediately without delay. It has shown that the proposed optimization system reduces energy consumption by up to $17.5 \%$ compared to actual driving patterns without increasing driving time.

When all the above and other optimization studies [13]-[19] for EVs are examined, it is remarkable that there is a need for an algorithm achieves the least cost-effective driving with the appropriate speed values by using the EV's engine effectively according to the road slope and bending values provided that the driver reaches the target in the desired time. In this study, in line the above-mentioned target, the least cost-effective driving characteristic is provided without compromising the time that the user wants to reach the target. Thus, the algorithm will contribute to the literature, related to autonomous driving studies in the world, not only to guide the vehicle, according to the road, but also to provide an economic driving model that can reach the target at the desired time for the user.

The major contributions of the paper can be summarized as follows:

- To achieve autonomous driving in electric vehicles, energy efficient driving optimization has been proposed.

- A software that provides an average of $13 \%$ less energy consumption has been realized.

- A software has been developed that considers the economic preference of the driver and increase the comfort of the driver on inclined and winding roads.

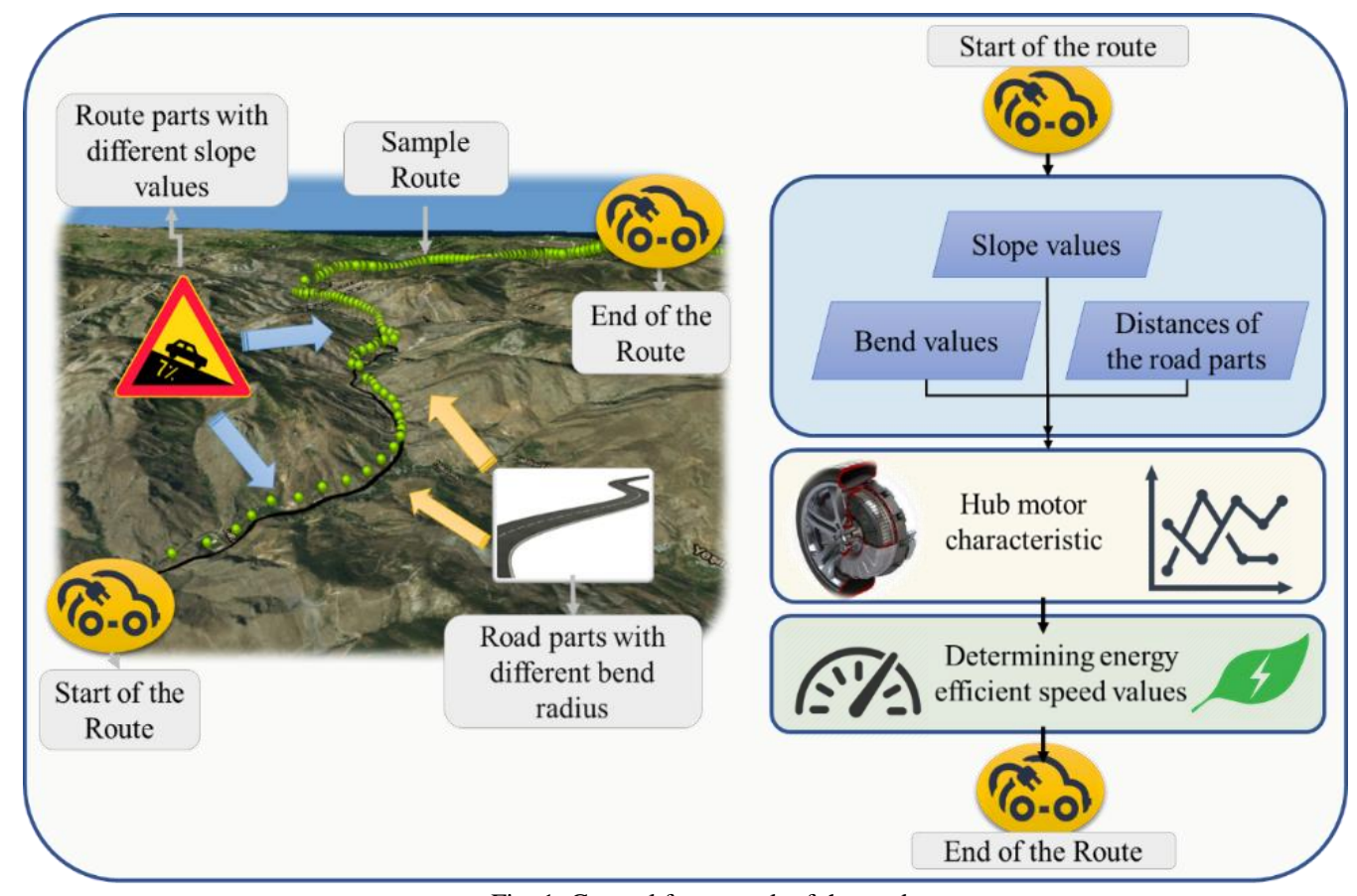

Fig. 1. General framework of the study

\section{PROBLEM DEFINITION}

The optimization of EVs can be achieved by two methods. The first method is to solve the optimization problem considering the parameters such as slope, traffic, speed limits, toll roads, cornering, and to prefer roads with less energy consumption. This problem is called Energy efficient route optimization problem. The second method is to optimize the most efficient driving, considering the vehicle engine efficiency according to the road conditions. This optimization problem is called Energy efficient driving optimization.

This study focuses on the energy efficient driving optimization. General representation of the study is shown in Fig. 1.

\section{A. Optimization Problem Formulation}

It is not possible for the driver to calculate at which speeds he/she should go for the most economical driving on different slope conditions. The driver is required to use the vehicle at the most efficient speeds, considering the road slope and bending characteristics of the road, constantly referring to the engine characteristics. The driver should also check whether the target has been reached at the desired time with these calculated speed values. This problem can only be solved by an optimization algorithm. The objective of the optimization problem is to deliver the vehicle to the target with the least possible energy consumption during the time the driver wants to reach the target. Therefore, the fitness function of the optimization problem depends on the current values $I_{n}, V$ battery voltage and 
time values $T_{n}$ drawn by the electric vehicle. $\mathrm{n}$ is the number of the road part that have different slope value.

The problem used in this study can be formulated as follows:

$$
F_{i}=\min \sum_{n=0}^{N} I_{n} \times V \times T_{n}
$$

where $F_{i}$ is the fitness function of $i$ th solution. Each set of solutions consists of the sum of the multiplication of the current values drawn by the vehicle on the different slope valued road segment and the time spent on the same road segment.

\section{B. Problem Assumptions}

- Regenerative braking has not been performed on downward sloping road sections.

- EVs are equipped a navigation center that has the required data, such as $\mathrm{x}, \mathrm{y}$ and $\mathrm{z}$ coordinates of the road, EV motor characteristic and route information.

- EVs have a speed control system that controls the vehicle speed according to proposed algorithm's energy efficient speeds.

- Maximum car speed used in the proposed algorithm is limited to hub motor maximum speed.

- The electric vehicle has adaptive cruise control that regulates its own speed relative to the vehicle in front.

\section{ESTABLISHING THE EV MODEL}

In optimization studies, all factors affecting energy consumption should be considered to model EVs correctly. In the modeling of EV used in this study, inertial force, gravitational force, rolling resistance force of wheels and aerodynamic force are considered [1], [4] as shown in Fig. 2.

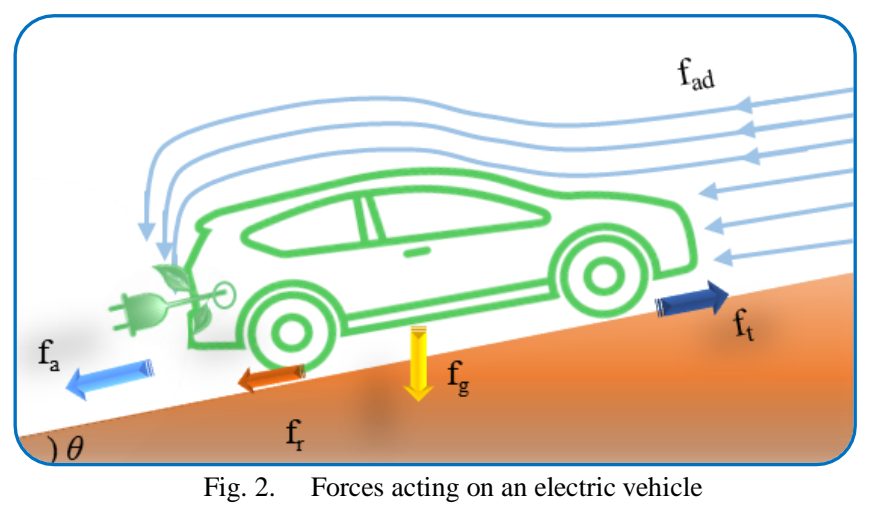

All the forces in Fig. 2 can be expressed mathematically as in the following equation.

$$
f_{t}=f_{a}+f_{g x}+f_{r}+f_{a d}
$$

where $f_{t}$ is the traction force required for the EV to move, $f_{a}$ is the inertial force, $f_{g x}$ is the gravitational force, $f_{r}$ is the rolling resistance force and $f_{a d}$ is the aerodynamic force. The aerodynamic force varies depending on the relative speed of the vehicle and the wind. The rolling resistance force depends on the friction between the tire and asphalt and does not change depending on the speed. The gravitational force depends on the slope of the road on which the vehicle climbs. The inertial force is a resistance which varies depending on the acceleration and mass of the vehicle.
Every force in (2) is calculated as follows.

\section{1) Aerodynamic Force}

The aerodynamic force can be calculated by [1], [4]

$$
f_{a d}=\frac{1}{2} \cdot \rho \cdot S \cdot C_{D} \cdot\left(v+v_{\text {wind }}\right)^{2}
$$

where $f_{a d}$ is the aerodynamic force, $\rho$ is air density, $S$ is the vehicle frontal area, $C_{D}$ is the aerodynamic drag coefficient, $v$ is the vehicle speed and $v_{\text {wind }}$ is the head wind speed.

The vertical surface area of the electric vehicle used in this study is calculated from the three-dimensional drawing of the vehicle as $1.57 \mathrm{~m}^{2}$. The air density $\rho$ is taken as $1.255 \mathrm{~kg} / \mathrm{m}^{3}$, the drag coefficient $C_{D}$ is taken as 0.229 .

2) Rolling Resistance Force

Rolling resistance refers to the energy consumed because of deformation when the tire contacts the road. In each turn of the wheel, the wheel tread area bends and deforms as it contacts the surface of the ground. Rubber is heated due to deformation and energy is lost in the form of heat. The rolling resistance force is

$$
\boldsymbol{f}_{r}=m \cdot g \cdot \mu
$$

where $m$ is the vehicle's mass, $g$ is the earth-surface gravitational acceleration and $\mu$ is the rolling coefficient. The rolling resistance force has been neglected in the subtraction of engine consumption characteristics of the electric vehicle because it does not change with the speed of the vehicle or the slope of the road.

\section{3) Gravitational Force}

Gravitational force is the force caused by the slope in the opposite direction to the direction of movement of the vehicle and can be calculated as follows

$$
\boldsymbol{f}_{\boldsymbol{g} x}=m \cdot g \cdot \sin (\boldsymbol{\theta})
$$

where $m$ is the vehicle's mass and $g$ is the earth-surface gravitational acceleration.

The weight of the electric vehicle used in the study was measured as $280 \mathrm{~kg}$. This value has been used to add variable slope resistance according to the road slope of the vehicle.

\section{4) Inertial Force}

When the speed of the moving objects changes, the force which is formed in the opposite direction to the movement direction is called inertial force. The inertial force is

$$
\boldsymbol{f}_{\boldsymbol{a}}=(\boldsymbol{m} / \boldsymbol{g}) \cdot \boldsymbol{a}
$$

where $m$ is the vehicle's mass, $g$ is the earth-surface gravitational acceleration and $a$ is the acceleration.

In this study, it was assumed that the EV was driven at constant speed in different slope intervals on the road by ignoring the acceleration resistance of the vehicle in determining the energy efficiency speed values. In addition, the resistance forces of other mechanical components were neglected as they did not change much with the vehicle speed and inclination value.

The total torque acting on the center of the wheel, since the total rim and tire radius of the vehicle is $26.72 \mathrm{~cm}$ can be calculated as below

$$
t_{t}=f_{t} * 0.2672
$$

where $t_{t}$ is the total torque and $f_{t}$ is the traction force. 


\section{DETERMINATION OF ROAD AND VEHICLE CHARACTERISTICS}

\section{A. Obtaining the Vehicle Characteristic}

In this study, Mitsuba M2096II Hub engine was used in the EV. The motor characteristic curve of the Mitsuba M2096II Hub engine shown in Fig. 3 is transferred to the MATLAB environment. By considering the forces acting on the vehicle and calculated in the previous section, the current drawn by the vehicle is calculated according to the total torque applied to the motor shaft.

The proposed algorithm determines the most efficient speed values by referring to the curve in Fig. 3, considering the road slope and bend radius within the time required to reach the target on the planned route.

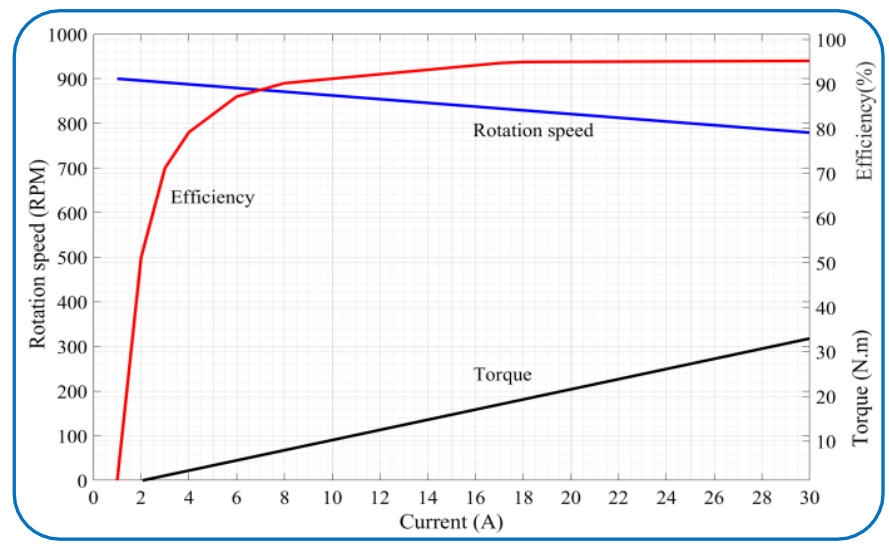

Fig. 3. Mitsuba M2096II hub engine curve

\section{B. Reading the Road Characteristic Using GIS}

Today, in the studies related to EVs, it is possible to collect, analyze and reach the results quickly with the help of Geographical Information Systems (GIS). GIS is a regular collection of computer hardware, software and geographic data designed to effectively collect, store, update, process, analyze and display all kinds of geographic information. GIS is also widely used in routing studies, such as data transformation, processing, arithmetic operations on database information, merging and determination of the route.

In this study, to test the developed algorithm, multiple different routes were used. GIS have been utilized to use the road characteristic of the route in the algorithm. A sample route and the characteristic road values are shown in Fig. 4.

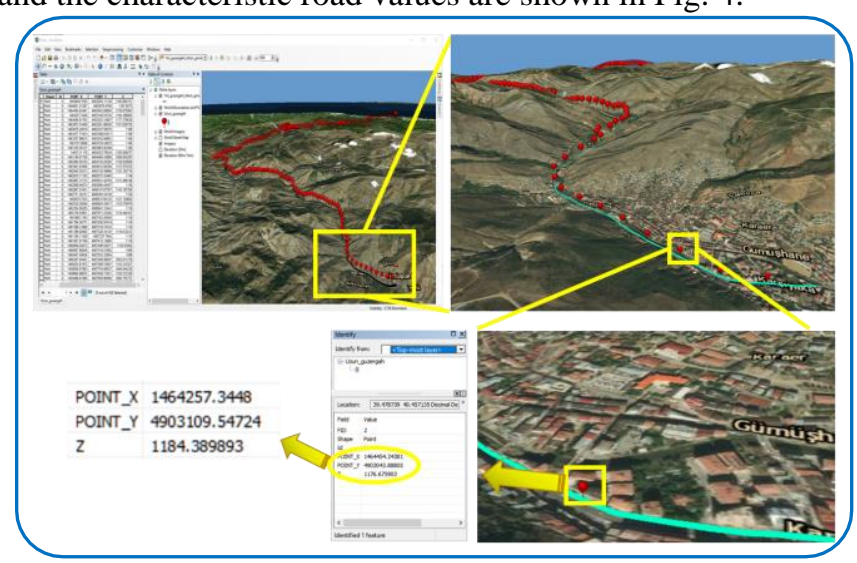

Fig. 4. Reading the route characteristic in GIS
All digital maps in GIS environment are stored in databases. To read the data of the sample road by the proposed algorithm, the road information in the GIS environment is converted to a text file so that the algorithm can read.

\section{Determining the Road Bend}

The Euclidean curvature approach can be used to the calculation of the bend radius of any part for the segmented road. The radius calculation for the circle given in Fig. 5. is formulated below.

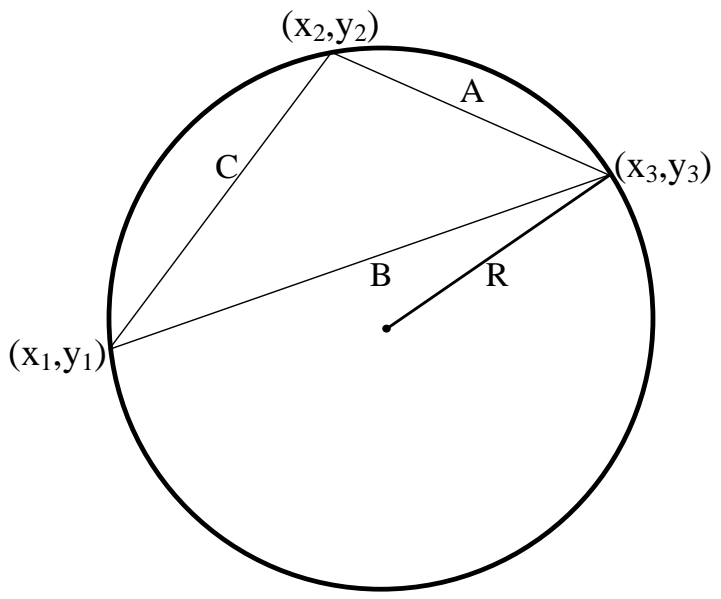

Fig. 5. Euclidean curvature calculation

$$
\begin{gathered}
R=\frac{A B C}{4 \sqrt{L(L-A)(L-B)(L-C)}} \\
L=\frac{1}{2}(A+B+C) \\
A=\sqrt{\left(x_{3}-x_{2}\right)^{2}+\left(y_{3}-y_{2}\right)^{2}} \\
B=\sqrt{\left(x_{3}-x_{1}\right)^{2}+\left(y_{3}-y_{1}\right)^{2}} \\
C=\sqrt{\left(x_{2}-x_{1}\right)^{2}+\left(y_{2}-y_{1}\right)^{2}}
\end{gathered}
$$

where $\mathrm{R}$ is the radius road bending. The maximum speed of the vehicle for a curve with radius $\mathrm{R}$ can be calculated as follows [1]

$$
\max _{\text {bend }}\left(\frac{k m}{h}\right)=\sqrt{127(\mu+\sigma) R}
$$

where $\boldsymbol{\mu}$ is the lateral friction coefficient and $\boldsymbol{\sigma}$ is the horizontal slope of the road. In this study, the horizontal slope of the road is not taken into consideration.

\section{OUTLINE OF THE ALGORITHM}

In this study, electric vehicle dynamic driving optimization has been studied for more efficient driving. The problem is a linear optimization problem with constraints. The objective function of the problem is to minimize the total energy of EV as calculated in equation 1 . The current to be consumed according to the torque acting on the drive system on different sloping parts of the road is taken from Fig. 3 according to equations 3-7. The two most important constraints are the maximum speed of the vehicle, according to the engine characteristics of the EV and the speed at which the EV can travel in the bends of the road.

For the problem described in this study, Genetic algorithm (GA) is used because of its ability to avoid local optimum 
solutions and converge to a global one [20]. GA is a stochastic powerful optimization method based on a random-based study logic. It has been successfully adapted to solve many optimization problems, including planning, handling and engineering [21]. The flowchart of the algorithm is shown in Fig. 6.

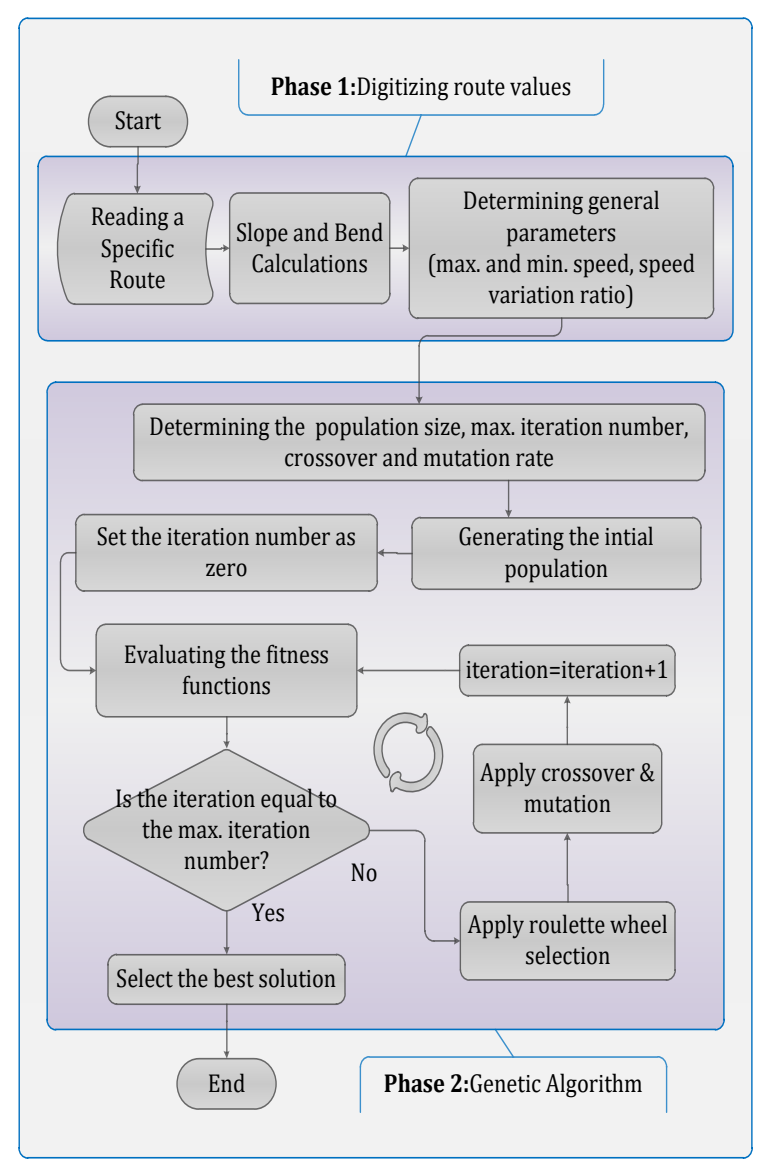

Fig. 6. Flowchart of the developed algorithm

In GA, each individual constituting the population represents a solution for the problem. In this study, each chromosome contains different speed values that the vehicle can travel along the route of the EVs. An individual gene contains the speed at which each vehicle can travel.

The main steps of the algorithm are as follows.

\section{A. Initializing the Population}

In this step the parameters of the study are determined. The main parameters are population size, maximum number of iterations, crossover, and mutation rate. The population consists of many chromosomes.

\section{B. Chromosome Generation}

Each individual in the population is called a chromosome. Identification of the number of the chromosomes in the population is very important. No definite judgment has been made for the size of the population set to be solved for different problems. When this value is too small, the algorithm is not able to find a good solution as a result of reducing the number of alternatives needed to find the best solution. The fact that the number of chromosomes in the solution set is too large also appears to be an effect that slows down the algorithm considerably. The best value should be determined by the behavior of the problem. A sample chromosome representation is shown in Fig. 7.

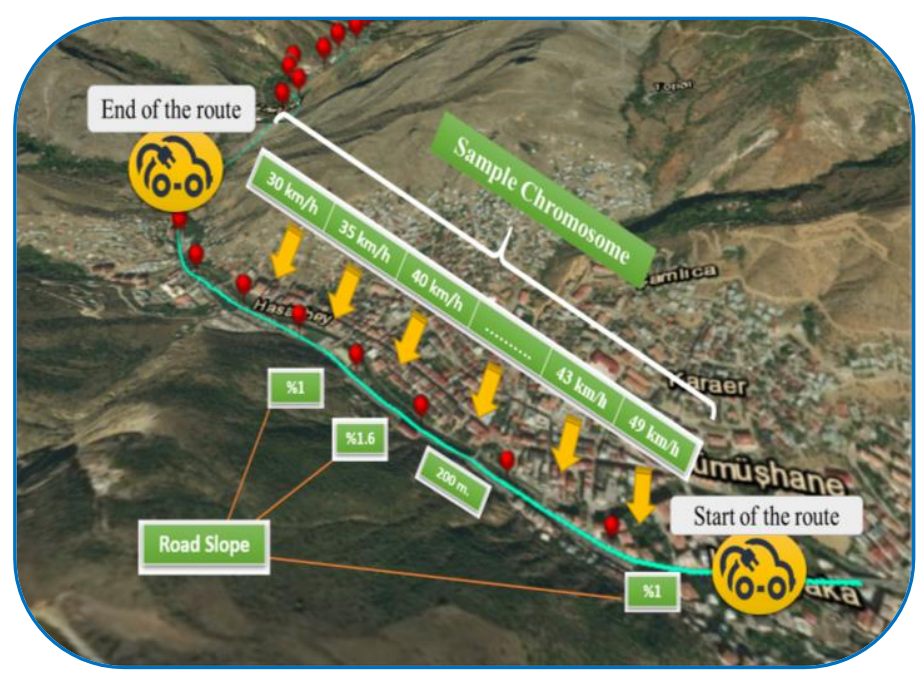

Fig. 7. Sample chromosome used for the proposed algorithm

Every chromosome is determined according to the following equations.

$$
X= \begin{cases}x_{i, j}=\operatorname{rand}\left(\operatorname{minV}_{j}, \max _{j}\right) & , j=1 \\ x_{i, j}=\operatorname{rand}\left(\operatorname{smin}_{j}, \operatorname{smax}_{j}\right) & , j>1\end{cases}
$$

Where $X$ is the chromosome of the algorithm, $i=1,2, \ldots, n_{p}$, $j=1,2, \ldots, k, n_{p}$ is the number of chromosomes in the population, $V$ is the speed values and $k$ is the number of the route parts.

$$
\begin{aligned}
& \operatorname{smin}_{j}=\left\{\begin{array}{cc}
\min _{j} & , \quad x_{i, j-1} \times l b<\operatorname{minV}_{j} \\
x_{i, j-1} \times l b & , \quad x_{i, j-1} \times l b \geq \min V_{j}
\end{array}\right. \\
& \operatorname{smax}_{j}=\left\{\begin{array}{cc}
\max _{j} & , \quad x_{i, j-1} \times h b \geq \max V_{j} \\
x_{i, j-1} \times h b & , \quad x_{i, j-1} \times h b<\max V_{j}
\end{array}\right.
\end{aligned}
$$

where $l b$ is acceleration lower limit coefficient and $h b$ is acceleration upper limit coefficient. These coefficients are used to determine the speed values that make up genes in the process of chromosome generation. Being extremely different from the previous speed value is not desirable as it is not possible in terms of the vehicle engine acceleration characteristic.

\section{Evaluating the Objective Functions}

The objective function shows how well the chromosomes in the population are. This function is very important for GA since the selection in GA is based on the objective function. The objective function is calculated from the fitness value as formulated in the second section of the study.

\section{Selection Procedure}

This procedure is the selection of two chromosomes from the population by considering their fitness values. Selection 
methods commonly used are roulette wheel selection, tournament selection and sequential selection. The selection of the roulette wheel is related to the area occupied by the fitness values of the chromosomes in the solution set on the wheel. Thus, non-healthy chromosomes have a chance to be selected. The selection probability of each chromosome in the population can be found by calculating the ratio of each chromosome's fitness value to the sum of the fitness values of all the chromosomes in the population. Good fitness values increase the selection probability of a chromosome being selected from a set of solutions. We selected a chromosome with a probability calculated by the following equation.

$$
p_{i}=\frac{f_{i}}{\sum_{j=1}^{k}\left(f_{j}\right)}
$$

where $\mathrm{k}$ is the number of all chromosomes in the population, $f_{i}$ is the fitness value of the $i$ th chromosome and $p_{i}$ is the selection probability $i$ th chromosome.

\section{E. Crossover}

The crossover operator is based on the formation of elite parent chromosomes by combining the characteristics of different population members in new individuals. For this purpose, two parent chromosomes in the population are randomly selected. The two common parts of the two selected parents are mutually crossed. The most important constraint here is that the randomly selected parts of the randomly selected parent chromosomes must belong to the same road segments in the problem. Sample crossover operation used in the algorithm is shown in Fig.8.

If the fitness value of the child chromosome is better than the first selected parent chromosome, the child chromosome is taken to the population instead of the parent chromosome.

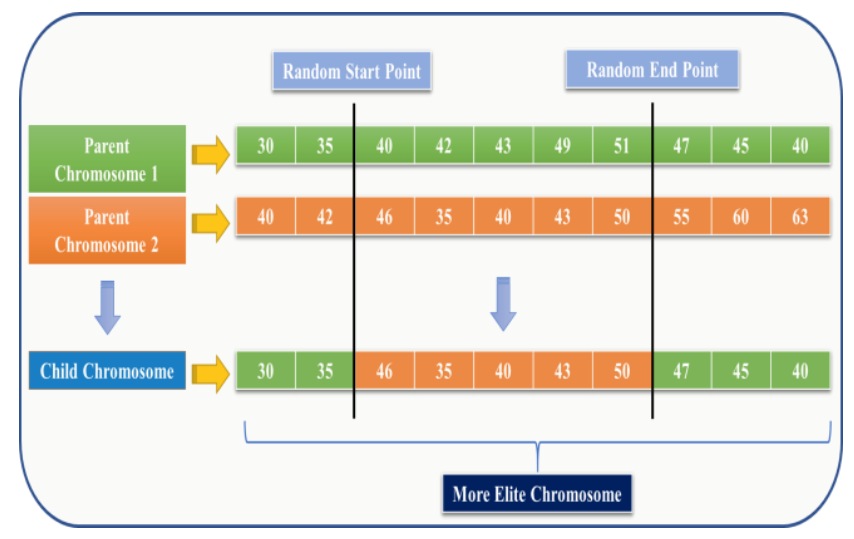

Fig. 8. Sample crossover operation used in the algorithm

\section{F. Mutation}

The mutation is the determination of the better chromosomes by changing the structure of the individuals to be transferred from the individuals in the solution set for the next generation. The mutation is carried out in order to ensure diversity and to reach the result faster by preventing the new solution for just copying from the previous solutions. Sample mutation operation used in the algorithm is shown in Fig. 9.

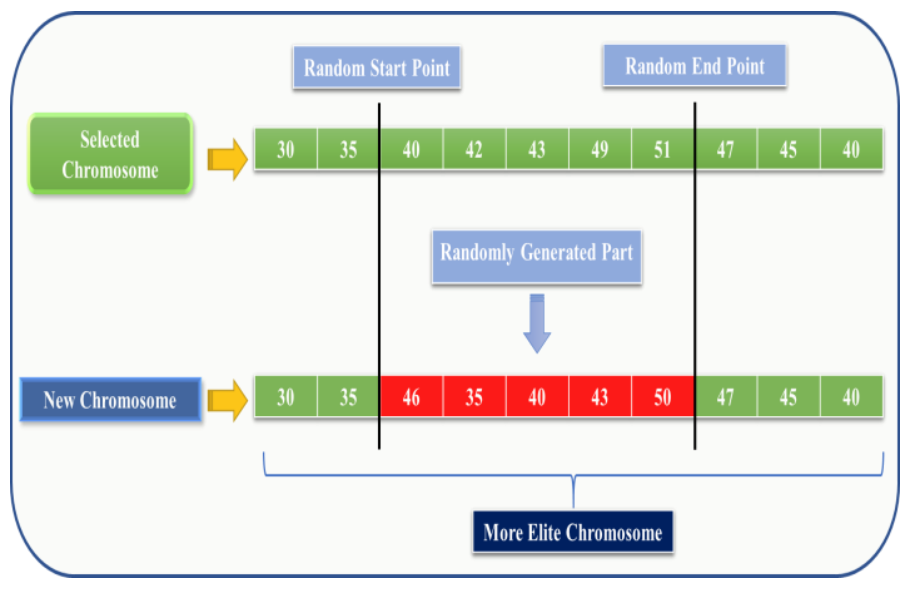

Fig. 9. Sample mutation operation used in the algorithm

\section{G. Determining the Termination Condition}

In this study firstly, the termination criterion is selected as the maximum number of iterations. At the end of many experimental studies, it is seen that the analytical convergence decreases when a certain number of cycles is exceeded. For this reason, it is chosen to reach the maximum efficiency value as the termination criterion of the algorithm.

\section{RESULTS AND DISCUSSION}

In this section, different experimental studies about the problem, vehicle model, road slope characteristics and the proposed algorithm were carried out to reveal the efficiency of the study. In this respect, a sample route with different road slope and bending characteristics is selected and discussed in detailed below.

\section{A. Details of the Route}

As the proposed approach in the study is to achieve the most energy efficient driving, according to the engine characteristics and different bending values of the road, we have selected the motorway between Trabzon-Gumushane provincial centers, which is approximately $100 \mathrm{~km}$ long as the sample route. The details of the route are shown in Table 1. Each line in this table gives the average characteristic of the 5 $\mathrm{km}$ segments of the route. The reasons for choosing the route are as follows; Having 0-7\% slope characteristics with different road segments, having low and high bending parts, performing efficiency analysis for short and long different route situations $(10,20, \ldots 100 \mathrm{~km}$ cases $)$ along the $0-100 \mathrm{~km}$ route. The slope and bending view of the route is shown in Fig. 10. 


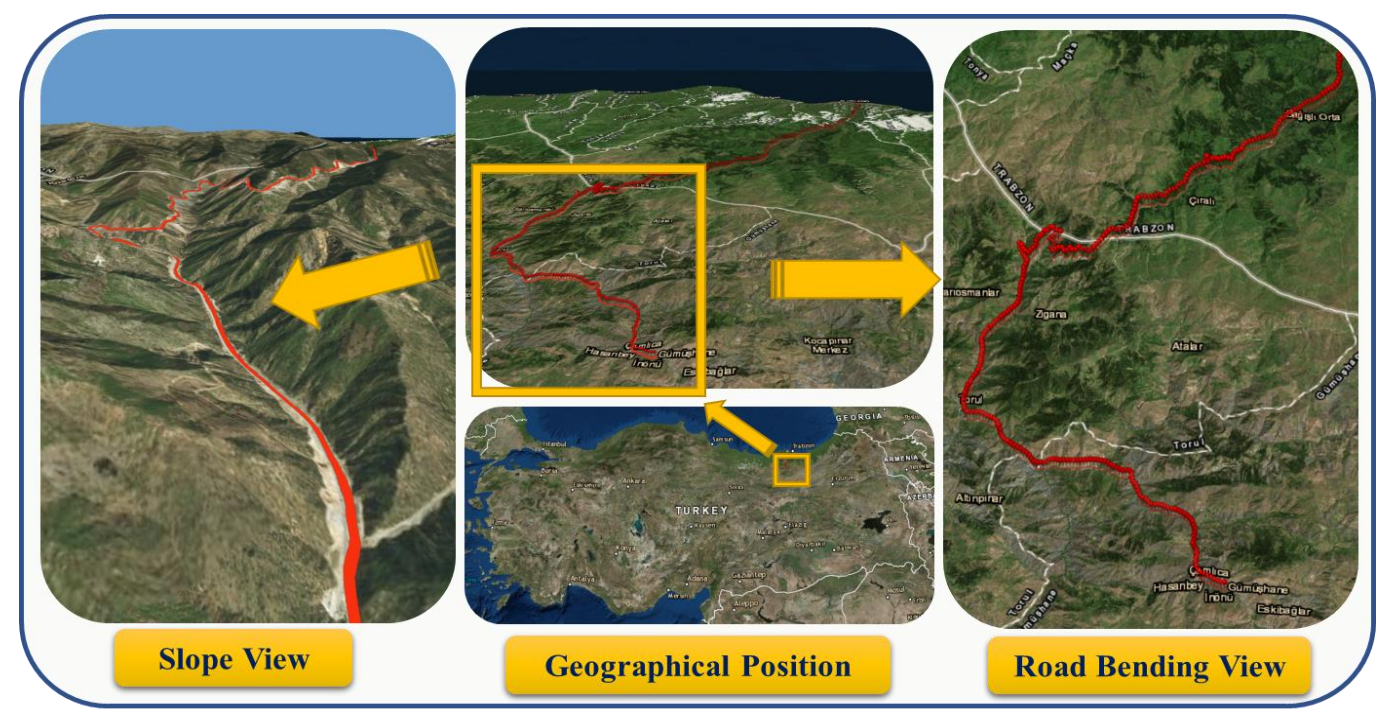

Fig. 10. Slope and bending view of the route

TABLE 1

ROAD CHARACTERISTICS

\begin{tabular}{|c|c|c|c|c|}
\hline $\begin{array}{r}\text { Part } \\
\text { number }\end{array}$ & $\begin{array}{c}\text { Road } \\
\text { part length }\end{array}$ & $\begin{array}{l}\text { Average } \\
\text { slope } \\
\text { value }\end{array}$ & $\begin{array}{l}\text { Average } \\
\text { slope } \\
\text { value } \\
\text { (degree) }\end{array}$ & $\begin{array}{l}\text { Minimum } \\
\text { bend radius }\end{array}$ \\
\hline 1 & $5.19 \mathrm{~km}$ & -0.010 & -0.58 & $357.96 \mathrm{~m}$ \\
\hline 2 & $5.07 \mathrm{~km}$ & -0.008 & -0.44 & $350.42 \mathrm{~m}$ \\
\hline 3 & $5.38 \mathrm{~km}$ & -0.010 & -0.56 & $266.75 \mathrm{~m}$ \\
\hline 4 & $5.10 \mathrm{~km}$ & -0.008 & -0.45 & $416.74 \mathrm{~m}$ \\
\hline 5 & $5.36 \mathrm{~km}$ & 0.004 & 0.23 & $315.02 \mathrm{~m}$ \\
\hline 6 & $5.06 \mathrm{~km}$ & 0.006 & 0.34 & $500.51 \mathrm{~m}$ \\
\hline 7 & $5.30 \mathrm{~km}$ & 0.044 & 2.52 & $127.43 \mathrm{~m}$ \\
\hline 8 & $5.21 \mathrm{~km}$ & 0.029 & 1.68 & $117.23 \mathrm{~m}$ \\
\hline 9 & $5.26 \mathrm{~km}$ & -0.008 & -0.47 & $157.46 \mathrm{~m}$ \\
\hline 10 & $5.13 \mathrm{~km}$ & -0.049 & -2.80 & $216.78 \mathrm{~m}$ \\
\hline 11 & $5.29 \mathrm{~km}$ & -0.053 & -3.05 & $124.01 \mathrm{~m}$ \\
\hline 12 & $5.23 \mathrm{~km}$ & -0.048 & -2.73 & $237.74 \mathrm{~m}$ \\
\hline 13 & $5.31 \mathrm{~km}$ & -0.029 & -1.64 & $440.19 \mathrm{~m}$ \\
\hline 14 & $5.10 \mathrm{~km}$ & -0.021 & -1.23 & $342.20 \mathrm{~m}$ \\
\hline 15 & $5.35 \mathrm{~km}$ & -0.021 & -1.23 & $256.40 \mathrm{~m}$ \\
\hline 16 & $5.17 \mathrm{~km}$ & -0.011 & -0.66 & $229.77 \mathrm{~m}$ \\
\hline 17 & $5.07 \mathrm{~km}$ & -0.011 & -0.62 & $460.59 \mathrm{~m}$ \\
\hline 18 & $5.23 \mathrm{~km}$ & -0.012 & -0.71 & $1388.86 \mathrm{~m}$ \\
\hline 19 & $5.29 \mathrm{~km}$ & -0.009 & -0.52 & $314.04 \mathrm{~m}$ \\
\hline 20 & $3.43 \mathrm{~km}$ & -0.006 & -0.35 & $396.35 \mathrm{~m}$ \\
\hline
\end{tabular}

\section{B. Case Studies}

The algorithm was run at different distances along the route to reveal the efficiency of the algorithm. The proposed algorithm for 10,20,30, $100 \mathrm{~km}$ long driving distances and the results of the vehicle driving at average speeds at the same distances were compared. For comparison, it is assumed that the vehicle travels at fixed average speeds named Desired average speed on the sample route. Current $\times$ Second values calculated according to road distances and desired average speed values are shown in Table 2 .
TABLE 2

CONSTANT AVERAGE SPEED CASE STUDY RESULTS

\begin{tabular}{|c|c|c|c|c|c|c|c|}
\hline & \multicolumn{6}{|c|}{ Desired Average Speeds $(\mathrm{km} / \mathrm{h})$} \\
\hline & & 50 & 60 & 70 & 80 & 90 & 100 \\
\hline \multirow{11}{*}{ 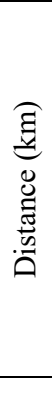 } & 10 & 9049 & 9252 & 9801 & 10601 & 11489 & 12563 \\
\hline & 20 & 15917 & 16928 & 18520 & 20744 & 23089 & 25705 \\
\hline & 30 & 31280 & 31628 & 33205 & 35755 & 38653 & 41993 \\
\hline & 40 & 59007 & 57339 & 57924 & 60065 & 62883 & 66359 \\
\hline & 50 & 68127 & 66036 & 66530 & 68787 & 71864 & 75758 \\
\hline & 60 & 70442 & 68411 & 69166 & 71822 & 75300 & 79851 \\
\hline & 70 & 76987 & 74867 & 75794 & 78977 & 83293 & 88933 \\
\hline & 80 & 83124 & 81596 & 83368 & 87543 & 93124 & 100044 \\
\hline & 90 & 89403 & 88695 & 91551 & 96948 & 103919 & 112308 \\
\hline & 100 & 94337 & 94633 & 98737 & 105380 & 113433 & 122823 \\
\hline & & \multicolumn{6}{|c|}{ Current x Seconds (AxS) } \\
\hline
\end{tabular}

The desired average speed values given in Table 2 are not applicable at all points of the route. When the maximum speeds are calculated considering the bend radius of the road, some of the applied average speeds are calculated below the desired values. In this case, applied average speed values occur. The desired average speed values and the applied average speed values are shown in Table 3.

TABLE 3

APPLIED AVERAGE SPEEDS

\begin{tabular}{|c|c|c|c|c|c|c|c|}
\hline & & \multicolumn{6}{|c|}{ Desired Average Speeds $(\mathrm{km} / \mathrm{h})$} \\
\hline & & 50 & 60 & 70 & 80 & 90 & 100 \\
\hline \multirow{10}{*}{ 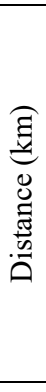 } & 10 & 50 & 60 & 70 & 80 & 89 & 98 \\
\hline & 20 & 50 & 60 & 70 & 80 & 89 & 98 \\
\hline & 30 & 50 & 60 & 70 & 80 & 89 & 98 \\
\hline & 40 & 50 & 60 & 69 & 78 & 87 & 95 \\
\hline & 50 & 50 & 60 & 69 & 78 & 86 & 94 \\
\hline & 60 & 50 & 60 & 69 & 78 & 86 & 93 \\
\hline & 70 & 50 & 60 & 69 & 78 & 86 & 94 \\
\hline & 80 & 50 & 60 & 69 & 78 & 87 & 94 \\
\hline & 90 & 50 & 60 & 69 & 78 & 87 & 95 \\
\hline & 100 & 50 & 60 & 69 & 78 & 87 & 95 \\
\hline & & \multicolumn{6}{|c|}{ Applied Average Speeds $(\mathrm{km} / \mathrm{h})$} \\
\hline
\end{tabular}


Gain value used in the comparisons is calculated by comparing the fitness function values obtained by the proposed algorithm and applied average speed case.

The gain value can be calculated by the following equation.

$$
\eta=\frac{E_{a s}-E_{p a}}{E_{a s}} \times 100
$$

where $E_{a s}$ is the energy consumed using the applied average speed value, and $E_{p a}$ is the energy consumed using the proposed algorithm.

To test the accuracy of the proposed algorithm, case studies have been carried out for many different situations. Case studies and results are as follows.

\section{Constant average speed case}

In this part, first, the energy consumptions for different arrival times on different routes were calculated using the developed algorithm and applied average speed. These two values were compared, and gains were calculated. In this case study, it is assumed that the driver chooses an average speed and goes constant at this speed. The results obtained from these two cases at different times are given in Table 4.
As shown in Table 4, the energy consumed by the vehicle for the same arrival times on the same route is reduced by the proposed algorithm and an average of $11.25 \%$ gain is obtained. This value shows that the driver is not able to make an energy efficient driving like the proposed algorithm considering the road characteristics and bending values.

In the proposed algorithm, the minimum arrival time for calculating the speed values was used. This value is essential for the vehicle and driver to reach the destination at the desired time. In determining the minimum arrival time of the proposed algorithm, $1 \mathrm{~km} / \mathrm{min}$, which is a suitable average value for cars, was taken into consideration.

\section{Constant distance case}

In contrast to the average speed case discussed in detail in the previous section, this section tested the performance of the algorithm at different speeds at the same distance. For this purpose, the performance of the algorithm was tested at different speeds between $45-70 \mathrm{~km} / \mathrm{h}$ at $98 \mathrm{~km}$. The results obtained are presented in Table 5

TABLE 4

CONSTANT AVERAGE SPEED CASE STUDY RESULTS

\begin{tabular}{lllll}
\hline Average Speed & \multicolumn{1}{c}{$60 \mathrm{~km} / \mathrm{h}$} & & & \\
\hline Distance & Time given & $\begin{array}{l}\text { Energy } \\
\text { (Proposed Algorithm) }\end{array}$ & $\begin{array}{l}\text { Energy } \\
\text { (Constant Speed) }\end{array}$ & Gain \\
\hline $9,77 \mathrm{~km}$ & $586 \mathrm{sec}$ & $8192 \mathrm{~A} \times \mathrm{sec}$ & $9254 \mathrm{~A} \times \mathrm{sec}$ & $11,5 \%$ \\
\hline $19,84 \mathrm{~km}$ & $1191 \mathrm{sec}$ & $15043 \mathrm{~A} \times \mathrm{sec}$ & $16928 \mathrm{~A} \times \mathrm{sec}$ & $11,1 \%$ \\
\hline $29,78 \mathrm{~km}$ & $1787 \mathrm{sec}$ & $27511 \mathrm{~A} \times \mathrm{sec}$ & $31628 \mathrm{~A} \times \mathrm{sec}$ & $13,0 \%$ \\
\hline $39,87 \mathrm{~km}$ & $2392 \mathrm{sec}$ & $51412 \mathrm{~A} \times \mathrm{sec}$ & $57321 \mathrm{~A} \times \mathrm{sec}$ & $10,3 \%$ \\
\hline $49,83 \mathrm{~km}$ & $2990 \mathrm{sec}$ & $59002 \mathrm{~A} \times \mathrm{sec}$ & $66011 \mathrm{~A} \times \mathrm{sec}$ & $10,6 \%$ \\
\hline $59,91 \mathrm{~km}$ & $3595 \mathrm{sec}$ & $61045 \mathrm{~A} \times \mathrm{sec}$ & $68389 \mathrm{~A} \times \mathrm{sec}$ & $10,7 \%$ \\
\hline $69,85 \mathrm{~km}$ & $4191 \mathrm{sec}$ & $66987 \mathrm{~A} \times \mathrm{sec}$ & $74849 \mathrm{~A} \times \mathrm{sec}$ & $10,5 \%$ \\
\hline $79,97 \mathrm{~km}$ & $4798 \mathrm{sec}$ & $72479 \mathrm{~A} \times \mathrm{sec}$ & $81604 \mathrm{~A} \times \mathrm{sec}$ & $11,2 \%$ \\
\hline $89,78 \mathrm{~km}$ & $5387 \mathrm{sec}$ & $78476 \mathrm{~A} \times \mathrm{sec}$ & $88735 \mathrm{~A} \times \mathrm{sec}$ & $11,6 \%$ \\
\hline $98,00 \mathrm{~km}$ & $5880 \mathrm{sec}$ & $83320 \mathrm{~A} \times \mathrm{sec}$ & $94703 \mathrm{~A} \times \mathrm{sec}$ & $12,0 \%$ \\
\hline
\end{tabular}

TABLE 5

CONSTANT DISTANCE CASE STUDY RESULTS

\begin{tabular}{lcccc}
\hline Distance: & $98,00 \mathrm{~km}$ & & & \\
\hline Time given & $\begin{array}{c}\text { Average } \\
\text { Speed }\end{array}$ & $\begin{array}{c}\text { Energy } \\
\text { (Proposed } \\
\text { Algorithm) }\end{array}$ & $\begin{array}{c}\text { Energy } \\
\text { (Constant Speed) }\end{array}$ & Gain \\
\hline $7840 \mathrm{sec}$ & $45 \mathrm{~km} / \mathrm{h}$ & $79842 \mathrm{~A} \times \mathrm{sec}$ & $96448 \mathrm{~A} \times \mathrm{sec}$ & $17,22 \%$ \\
\hline $7056 \mathrm{sec}$ & $50 \mathrm{~km} / \mathrm{h}$ & $81481 \mathrm{~A} \times \mathrm{sec}$ & $94312 \mathrm{~A} \times \mathrm{sec}$ & $13,60 \%$ \\
\hline $6415 \mathrm{sec}$ & $55 \mathrm{~km} / \mathrm{h}$ & $81871 \mathrm{~A} \times \mathrm{sec}$ & $93857 \mathrm{~A} \times \mathrm{sec}$ & $12,77 \%$ \\
\hline $5880 \mathrm{sec}$ & $60 \mathrm{~km} / \mathrm{h}$ & $83561 \mathrm{~A} \times \mathrm{sec}$ & $94705 \mathrm{~A} \times \mathrm{sec}$ & $11,77 \%$ \\
\hline $5428 \mathrm{sec}$ & $65 \mathrm{~km} / \mathrm{h}$ & $86325 \mathrm{~A} \times \mathrm{sec}$ & $96485 \mathrm{~A} \times \mathrm{sec}$ & $10,53 \%$ \\
\hline $5040 \mathrm{sec}$ & $70 \mathrm{~km} / \mathrm{h}$ & $90527 \mathrm{~A} \times \mathrm{sec}$ & $102900 \mathrm{~A} \times \mathrm{sec}$ & $12,02 \%$ \\
\hline
\end{tabular}

Table 5 shows that an average of $13 \%$ gain is obtained. Also, the graphical representation of the results in Table is presented as in figure 11. With above different case studies, it is shown that the proposed algorithm is very useful in terms of energy efficiency.

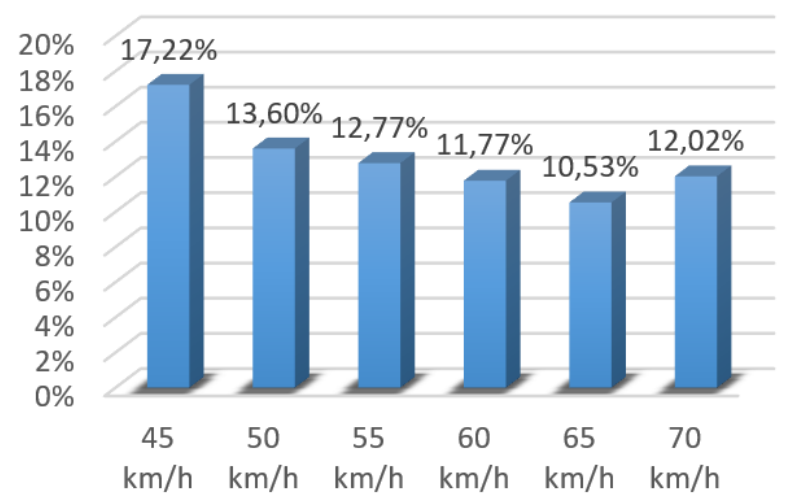

Fig. 11. Gain values according to different speeds.

\section{CONCLUSIONS}

Electric vehicle technologies are becoming more and more common every day. Basically, the subject of autonomous driving consists of two titles as autonomous tracking of the road and determination of autonomous speeds. 
It is not possible for vehicle drivers to determine the most energy-efficient speed profile by considering road slope, bending and vehicle engine characteristics. For this purpose, artificial intelligence is needed.

In this study, efficient driving optimization of electric vehicles was realized. For this purpose, modelling of the electric vehicle was performed and as an optimization problem the problem parameters were calculated. The characteristics of a commonly used EV motor were modelled. In order to solve the problem with GA, which is a powerful method of artificial intelligence methods, the general working framework was determined, and the algorithm was integrated to the study. The interaction between GIS and GA was provided. The performance of the proposed algorithm was tested with different case studies on the determined sample routes. The results obtained showed that the developed algorithm achieved an average of $13 \%$ gain with an efficient driving profile.

With this study, electric vehicles will be used more efficiently in terms of energy. Thus, environmental efficiency will be achieved.

\section{FUTURE WORKS}

In the future study, the integration of the developed algorithm on an electric vehicle and the autonomous driving of the electric vehicle is planned with the help of a navigation to be developed. Also, further development of the study can be realized by including parameters such as traffic, road condition etc. by using larger data.

\section{ACKNOWLEDGMENTS}

This research was supported by Scientific Research Projects Coordination Unit of Gumushane University by the 16.F5112.02.01 project number. The authors thank the Scientific Research Projects Coordination Unit of Gumushane University and the editors and anonymous referees for helpful feedback on earlier drafts.

\section{REFERENCES}

[1] H. Kumaş, C. Gencer, and H. Maraş, "Ağir araçlar için yol eğimi ve viraj yariçapi dikkate alinarak en hizli güzergâhin belirlenmesi," J. Fac. Eng. Archit. Gazi Univ., vol. 27, no. 2, pp. 385-395, 2012.

[2] A. Artmeier and J. Haselmayr, "The optimal routing problem in the context of battery-powered electric vehicles," in Workshop: CROCS at $\ldots, 2010$, no. APRIL 2010, pp. 1-13, [Online]. Available: http://www.cis.cornell.edu/ics/compsust-org/crocs-atcpaior10/papers/crocs-at-cpaior10-Artmeier.pdf.

[3] M. Sachenbacher, M. Leucker, A. Artmeier, and J. Haselmayr, "Efficient Energy-Optimal Routing for Electric Vehicles," in Proc. Twenty-Fifth AAAI Conference on Artificial Intelligence, 2011, no. January 2011, pp. 1402-1407.

[4] A. M. Bozorgi, M. Farasat, and A. Mahmoud, "A Time and Energy Efficient Routing Algorithm for Electric Vehicles Based on Historical Driving Data," IEEE Trans. Intell. Veh., vol. 2, no. 4, pp. 308-320, 2017, doi: 10.1109/tiv.2017.2771233.

[5] Y. Wang, J. Jiang, and T. Mu, "Context-aware and energy-driven route optimization for fully electric vehicles via crowdsourcing," IEEE Trans. Intell. Transp. Syst., vol. 14, no. 3, pp. 1331-1345, 2013, doi: 10.1109/TITS.2013.2261064.

[6] M. F. and O. Basir, "Optimal energy/time routing in battery-powered vehicles," 2016

[7] O. Rawashdeh and R. Abousleiman, "Electric vehicle modelling and energy-efficient routing using particle swarm optimisation," IET Intell. Transp. Syst., vol. 10, no. 2, pp. 65-72, Mar. 2016, doi: 10.1049/ietits.2014.0177.
[8] C. Li, T. Ding, X. Liu, and C. Huang, "An Electric Vehicle Routing Optimization Model With Hybrid Plug-In and Wireless Charging Systems," IEEE Access, vol. 6, pp. 27569-27578, 2018, doi: 10.1109/ACCESS.2018.2832187.

[9] M. Vajedi and N. L. Azad, "Ecological adaptive cruise controller for plug-in hybrid electric vehicles using nonlinear model predictive control," IEEE Trans. Intell. Transp. Syst., vol. 17, no. 1, pp. 113-122, 2016, doi: 10.1109/TITS.2015.2462843.

[10] Z. Lin, "Optimizing and Diversifying Electric Vehicle Driving Range for U.S. Drivers," Transp. Sci., vol. 48, no. 4, pp. 635-650, 2014, doi: 10.1287/trsc.2013.0516.

[11] R. Cook, A. Molina-Cristobal, G. Parks, C. Osornio Correa, and P. J. Clarkson, "Multi-objective Optimisation of a Hybrid Electric Vehicle: Drive Train and Driving Strategy," in Evolutionary Multi-Criterion Optimization, S. Obayashi, K. Deb, C. Poloni, T. Hiroyasu, and T. Murata, Eds. Berlin, Heidelberg: Springer Berlin Heidelberg, 2007, pp. 330-345.

[12] L. Kang, H. Shen, and A. Sarker, "Velocity Optimization of Pure Electric Vehicles with Traffic Dynamics Consideration," in 2017 IEEE 37th International Conference on Distributed Computing Systems (ICDCS), Jun. 2017, pp. 2206-2211, doi: 10.1109/ICDCS.2017.220.

[13] J. Huang, Y. Liu, M. Liu, M. Cao, and Q. Yan, "Multi-Objective Optimization Control of Distributed Electric Drive Vehicles Based on Optimal Torque Distribution," IEEE Access, vol. 7, pp. 16377-16394, 2019, doi: 10.1109/ACCESS.2019.2894259.

[14] X. Wu, D. Freese, A. Cabrera, and W. A. Kitch, "Electric vehicles' energy consumption measurement and estimation," Transp. Res. Part D Transp. Environ. vol. 34, pp. 52-67, 2015, doi: 10.1016/j.trd.2014.10.007.

[15] H. Mehrjerdi and R. Hemmati, "Stochastic model for electric vehicle charging station integrated with wind energy," Sustain. Energy Technol. Assessments, vol. 37, no. October 2019, p. 100577, Feb. 2020, doi: 10.1016/j.seta.2019.100577.

[16] F. Orecchini, A. Santiangeli, and F. Zuccari, "Hybrid-electric system truth test: Energy analysis of Toyota Prius IV in real urban drive conditions," Sustain. Energy Technol. Assessments, vol. 37, no. December 2018, p. 100573, Feb. 2020, doi: 10.1016/j.seta.2019.100573.

[17] C. Bian, G. Yin, L. Xu, and N. Zhang, "Active collision algorithm for autonomous electric vehicles at intersections," IET Intell. Transp. Syst., vol. 13, no. 1, pp. 90-97, 2019, doi: 10.1049/iet-its.2018.5178.

[18] X. Dong, Q. Lin, M. Xu, and Y. Cai, "Artificial bee colony algorithm with generating neighbourhood solution for large scale coloured traveling salesman problem," IET Intell. Transp. Syst., vol. 13, no. 10, pp. 1483-1491, Oct. 2019, doi: 10.1049/iet-its.2018.5359.

[19] A. Fukushima, T. Yano, S. Imahara, H. Aisu, Y. Shimokawa, and Y. Shibata, "Prediction of energy consumption for new electric vehicle models by machine learning," IET Intell. Transp. Syst., vol. 12, no. 9, pp. 1174-1180, Nov. 2018, doi: 10.1049/iet-its.2018.5169.

[20] W. B. A. Karaa, A. S. Ashour, D. Ben Sassi, P. Roy, N. Kausar, and N. Dey, "Medline text mining: An enhancement genetic algorithm based approach for document clustering," Intell. Syst. Ref. Libr., vol. 96, pp. 267-287, 2016, doi: 10.1007/978-3-319-21212-8_12.

[21] A. Hiassat, A. Diabat, and I. Rahwan, "A genetic algorithm approach for location-inventory-routing problem with perishable products," J. Manuf. Syst., vol. 42, pp. 93-103, Jan. 2017, doi: 10.1016/j.jmsy.2016.10.004.

\section{BIOGRAPHIES}

HASAN EROĞLU received the B.S., M.S., and Ph.D. degrees in Electrical and Electronics Engineering from the University of

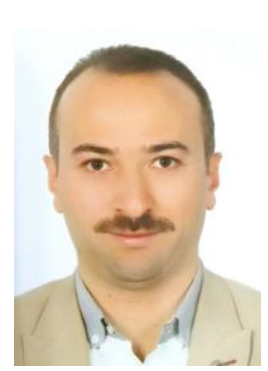
Selcuk, Konya, Turkey in 2007, 2009, and 2014. From 2010 to 2015, he was a research assistant in Gumushane University. He has been an assistant professor since 2015 . He has been working at Recep Tayyip Erdogan University since 2020. His research and professional interests include: Electrical engineering, optimization of energy transmission lines, renewable energy systems, geographic 
information systems in power systems, energy quality and decision support systems.

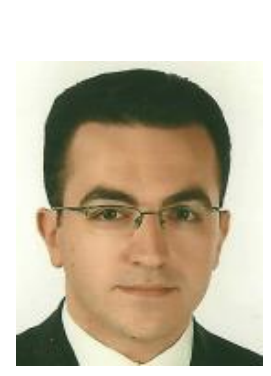

YASIN OĞUZ received the B.S., M.S., and Ph.D. degrees in Electrical and Electronics Engineering from Karadeniz Technical University, Trabzon, Turkey in 1998, 2002, and 2008.

From 1999 to 2001 he was a research assistant and from 2001 to 2011 he was a lecturer in Karadeniz Technical University. He has been an assistant professor since 2011. Between 2011 and 2013, he worked as an assistant professor at Avrasya University. He has been working at Gumushane University since 2013. His research and professional interests include: Electronics, Communication, Electromagnetic, Microwave and Antenna Technologies. 